\title{
In reply: Is an intravenous bolus of dexmedetomidine really a safe and effective option in treating shivering following neuraxial anesthesia?
}

\author{
Christina Lamontagne, MD, FRCPC (D) Sandra Lesage, MD, FRCP • \\ Édith Villeneuve, MD, FRCP · Elsa Lidzborski, MD • \\ Alex Derstenfeld, BASc, BCL, LLB · Chantal Crochetière, MD, FRCP
}

Received: 12 June 2019/Revised: 12 June 2019/Accepted: 17 June 2019/Published online: 1 July 2019

(C) Canadian Anesthesiologists' Society 2019

\section{To the Editor,}

We thank Dr. Bhakta and colleagues for their interest and considered criticism of our article entitled, "Intravenous dexmedetomidine for the treatment of shivering during Cesarean delivery under neuraxial anesthesia: a randomized-controlled trial". ${ }^{1}$

Our study was conducted at a mother and child hospital centre where meperidine is no longer used or available, because of both safety concerns and the lack of indication for its use in pain management. ${ }^{2}$ Furthermore, in our study, we did not claim that dexmedetomidine is safer than meperidine, but rather that no significant adverse effects were observed when compared with placebo. Indeed, a study comparing dexmedetomidine and meperidine for the treatment of shivering during Cesarean delivery is currently underway at an adult hospital centre within our university network (ClinicalTrials.gov identifier: NCT03115047); we too look forward to reviewing their findings, and it is our hope that their will further support the use of dexmedetomidine in such an application.

We hope that this study aids to convince readers what we know to be true in clinical practice-i.e., over ten years' experience using dexmedetomidine to treat perioperative shivering in pediatric and obstetric populations at our hospital centre has shown no adverse effects and is evidence of dexmedetomidine's excellent safety profile. In

C. Lamontagne, MD, FRCPC $(\bowtie) \cdot S$. Lesage, MD, FRCP .

É. Villeneuve, MD, FRCP · E. Lidzborski, MD .

C. Crochetière, MD, FRCP

CHU Sainte-Justine, Montreal, QC, Canada

e-mail: christina.lamontagne@umontreal.ca

A. Derstenfeld, BASc, BCL, LLB

Faculty of Medicine, McGill University, Montreal, QC, Canada the obstetrical context, the absence of significant bradycardia following administration of dexmedetomidine may be explained by the fact that the agent was administered immediately after childbirth when patients are relatively tachycardic. Indeed, if the medication was to be administered immediately following neuraxial anesthesia, and notably spinal anesthesia concomitant with an intravenous infusion of phenylephrine, the risk of bradycardia would likely be greater. Furthermore, the absence of any significant hypotension and sedation observed in our study is likely because of the small doses of dexmedetomidine administered $\left(0.25-0.5 \mu \mathrm{g} \cdot \mathrm{kg}^{-1}\right)$. We hope that further studies will confirm the relative safety of dexmedetomidine for the treatment of shivering during Cesarean delivery under neuraxial anesthesia.

Conflicts of interest None declared.

Editorial responsibility This submission was handled by Dr. Hilary P. Grocott, Editor-in-Chief, Canadian Journal of Anesthesia.

\section{References}

1. Bhakta P, Karim HM, Vassallo MC. Is an intravenous bolus of dexmedetomidine really a safe and effective option in treating shivering following neuraxial anesthesia? Can J Anesth 2020; 67; DOI: https://doi.org/10.1007/s12630-019-01429-1.

2. Lamontagne C, Lesage S, Villeneuve E, Lidzborski E, Derstenfeld $A$, Crochetière $C$. Intravenous dexmedetomidine for the treatment of shivering during cesarean delivery under neuraxial anesthesia: a randomized-controlled trial. Can J Anesth 2019; DOI: https://doi. org/10.1007/s12630-019-01354-3.

Publisher's Note Springer Nature remains neutral with regard to jurisdictional claims in published maps and institutional affiliations. 